15

\title{
Применение ИК микроскопии для прецизионного контроля диффузионных профилей распределения примесей железа и хрома в халькогенидах цинка
}

\author{
(C) Т.В. Котерева, В.Б. Иконников, Е.М. Гаврищук, А.М. Потапов, Д.В. Савин
}

Институт химии высокочистых веществ им. Г.Г. Девятых РАН, 603950 Нижний Новгород, Россия

e-mail: kotereva@ihps.nnov.ru

(Поступило в Редакцию 22 ноября 2017 г.)

Предложена методика для прецизионного, экспрессного и неразрушающего контроля поведения допанта в лазерных средах на основе халькогенидов цинка. Полученные результаты показывают возможность определения методом ИК спектроскопии в сочетании с ИК микроскопом концентрационных профилей допанта в виде ионов $\mathrm{Fe}^{2+}$ и $\mathrm{Cr}^{2+}$ в халькогенидах цинка в интервале концентраций от $5 \cdot 10^{17}$ до $2.5 \cdot 10^{20} \mathrm{at} / \mathrm{cm}^{3}$ с пространственным разрешением до нескольких микрометров. Определены диффузионные профили при солегировании халькогенидов цинка несколькими примесями одновременно.

DOI: 10.21883/JTF.2018.07.46189.2572

\section{Введение}

Халькогениды цинка, легированные двухвалентными ионами хрома и железа, являются перспективными материалами для создания активных сред лазеров, излучающих в среднем ИК диапазоне $(1.9-5 \mu \mathrm{m})$ [1-5]. Источники лазерного излучения данного диапазона широко используются в самых различных областях, включая молекулярную спектроскопию, мониторинг окружающей среды, медицину, дальнометрию, оптическую связь и др. Выходные характеристики лазеров на $\mathrm{ZnSe}(\mathrm{S}): \mathrm{Cr}^{2+}\left(\mathrm{Fe}^{2+}\right)$ во многом зависят от способа введения допанта и структуры материала генерирующей среды $[3,6]$. Применяют различные способы изготовления лазерных сред: диффузионное легирование предварительно синтезированного материала, чаще всего полученного методом химического осаждения из газовой фазы (CVD), легирование в процессе выращивания из расплава, физическое осаждение из пара (PVD) [3,5].

Очень важно иметь информацию о распределении допанта по объему образца, т. е. о его концентрационном профиле, форма которого может оказывать влияние на лазерные свойства среды. Знание профиля позволяет вычислить коэффициенты диффузии атомов допанта, величина которых в значительной степени зависит от природы структурных дефектов матрицы и, следовательно, от способа и условий получения материала. Поэтому для создания лазерных материалов с заданными свойствами необходима разработка прецизионных методик их характеризации.

Существуют различные способы исследования распределения примесей в образцах халькогенидов цинка. Среди них можно выделить методы элементного анализа - это лазерная масс-спектрометрия (ЛМС) и вторичная ионная масс-спектрометрия (ВИМС). В ЛМС локальность метода не всегда достаточна и составляет $\sim 100 \mu \mathrm{m}$. ВИМС позволяет определять полное содержание допанта с разрешением до $10 \mu \mathrm{m}$. Однако эти методы являются дорогостоящими и трудоемкими, кроме того, в процессе исследования образец разрушается и становится непригодным к дальнейшему использованию.

Применяются оптические методики с использованием лазерного излучения на длине волны в области поглощения примеси $[7,8]$. Их недостатками являются значительные ошибки измерений при наложении полос в случае солегирования несколькими элементами, необходимость учета поглощения атмосферы. Кроме того, для исследования необходимо наличие источников излучения на длине волны, близкой к максимуму интенсивных полос поглощения $\mathrm{Cr}^{+2}, \mathrm{Fe}^{+2}$.

Используемый в $[9,10]$ способ измерения интегральной оптической плотности в видимом диапазоне имеет низкую чувствительность и не пригоден при солегировании. Метод снятия тонких слоев с применением ИК спектроскопии имеет высокую точность, но использование сложной математической обработки затрудняет интерпретацию результатов $[11,12]$.

Таким образом, большая трудоемкость и длительность подготовки образцов существенно ограничивает использование существующих методик для исследования большого числа образцов, поэтому создание эффективного и экспрессного способа исследования диффузионных профилей является актуальным.

Целью настоящей работы является разработка методики определения методом ИК спектроскопии концентрационных профилей допанта в виде ионов $\mathrm{Fe}^{2+}$ и $\mathrm{Cr}^{2+}$ в халькогенидах цинка в интервале концентраций от $5 \cdot 10^{17}$ до $2.5 \cdot 10^{20} \mathrm{at} / \mathrm{cm}^{3}$. Метод ИК фурье-спектроскопии является неразрушающим, чувствительным в области поглощения двухвалентных ионов примесей переходных металлов в халькогенидах цинка, обладает 
быстродействием, а в сочетании с ИК микроскопом обеспечивает локальный анализ образцов с пространственным разрешением до нескольких $\mu \mathrm{m}$.

\section{1. Методика эксперимента}

В основе методики лежит регистрация спектров поглощения образцов $\mathrm{ZnS}: \mathrm{Cr}^{2+}, \mathrm{ZnSe}: \mathrm{Cr}^{2+}, \mathrm{ZnS}_{\mathrm{Fe}^{2+}}$, $\mathrm{ZnSe:Fe}{ }^{2+}$ при прохождении узкого пучка излучения в направлении, перпендикулярном направлению диффузии. Проведение измерений состояло в регистрации зависимости интенсивности излучения, прошедшего через анализируемый образец, от частоты ИК излучения в спектральном диапазоне $7300-1000 \mathrm{~cm}^{-1}(1.4-10 \mu \mathrm{m})$, при этом природу примеси определяли по положению спектральной линии поглощения на шкале частот. Концентрация примесей вычислялась по площади соответствующих линий в ИК спектрах.

\section{1. Подготовка образцов к анализу}

Объектом исследования являлись образцы $\mathrm{ZnS}, \mathrm{ZnSe}$, полученные методом химического осаждения из газовой фазы (CVD) и подвергавшиеся послеростовому отжигу или высокотемпературной газостатической обработке (горячее изостатическое прессование - НIP). Анализировались образцы с двумя характерными видами профиля распределения. Легированные образцы халькогенидов цинка первого типа (внешнее легирование) были получены посредством нанесения пленок железа или хрома толщиной от 1 до $10 \mu \mathrm{m}$ на одну или две противоположные поверхности образцов $\mathrm{ZnS}$ и $\mathrm{ZnSe}$. Далее осуществлялся процесс диффузии во время отжига при $T=950-1050^{\circ} \mathrm{C}$ в атмосфере аргона под давлением $\sim 1 \mathrm{~atm}$. в течение 5-7 суток или НIP обработки в атмосфере аргона в течение 30-60 h при давлении $1000 \mathrm{~atm}$ и температуре $1200-1300^{\circ} \mathrm{C}$.

Образцы второго типа (внутреннее легирование) были изготовлены по оригинальной технологии. Вначале на образцы CVD-ZnSe наносилась пленка хрома или железа. Далее для формирования легированного ионами $\mathrm{Cr}^{2+}$ или $\mathrm{Fe}^{2+}$ приповерхностного слоя образцы отжигались в запаянных кварцевых ампулах при температуре $1050^{\circ} \mathrm{C}$ в атмосфере аргона под давлением $\sim 1 \mathrm{~atm}$ в течение 1 -х суток для образцов с хромом и 2-х суток для образцов с железом. Затем образцы подвергались высококачественному химикомеханическому полированию и помещались в CVDреактор для доращивания слоя $\mathrm{ZnSe}$ необходимой толщины на поверхности, легированной ионами $\mathrm{Cr}^{2+}$ и $\mathrm{Fe}^{2+}$. В результате получалась трехслойная структура $\mathrm{ZnSe}-$ $\mathrm{ZnSe}: \mathrm{Cr}^{2+}\left(\mathrm{Fe}^{2+}\right)-\mathrm{ZnSe}$ толщиной до $8 \mathrm{~mm}$. С целью создания необходимого концентрационного профиля ионов допанта проводилась HIP-обработка синтезированной структуры.

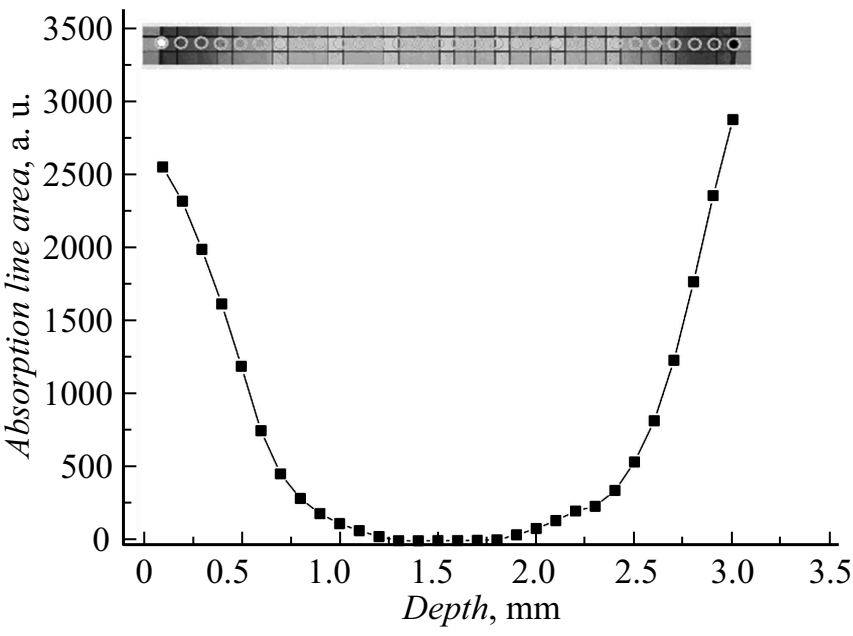

Рис. 1. Фотоизображение позиций регистрации спектров в образце $\mathrm{ZnS}$ с двухсторонним легированием (шаг $100 \mu \mathrm{m}$ ) и полученный распределительный профиль примеси $\mathrm{Fe}^{2+}$ вдоль направления диффузии.

Для измерения диффузионного профиля примесей хрома и железа в халькогенидах цинка вырезались плоскопараллельные пластины толщиной 2-4 mm в плоскости, параллельной направлению диффузионного потока. Образцы механически полировали с двух сторон, измеряли толщину микрометром, очищали поверхности спиртом и помещали на предметный столик микроскопа.

\section{2. Проведение измерений}

Спектры пропускания образцов регистрировались с помощью ИК фурье-спектрометра Tensor-27 (Bruker) в комплексе с ИК микроскопом HYPERION 2000, с использованием объектива с 15-кратным увеличением и числовой апертурой $\mathrm{NA}=0.4$. Пространственное разрешение микроскопа на длинах волн поглощения примесей железа и хрома составляло $2-5 \mu \mathrm{m}$, спектральное разрешение $4 \mathrm{~cm}^{-1}$. С помощью диафрагмы из излучения, выходящего из интерферометра, формировался пучок квадратного сечения размером $50 \times 50 \mu \mathrm{m}$. В процессе проведения измерений образец с помощью автоматизированного микрометрического столика перемещался относительно этого пучка с шагом от 20 до $100 \mu \mathrm{m}$. В качестве детектора использовался охлаждаемый детектор КРТ (кадмий, ртуть, теллур), делитель пучка $\mathrm{KBr}$, источником ИК излучения служил глобар (стержень из $\mathrm{SiC})$.

Перед проведением измерений для выбора позиций регистрации ИК спектров проводился визуальный контроль поверхности образца с помощью оптического объектива, фокус которого совпадал с фокусом ИК микроскопа. Шаг сканирования выбирался, исходя из 


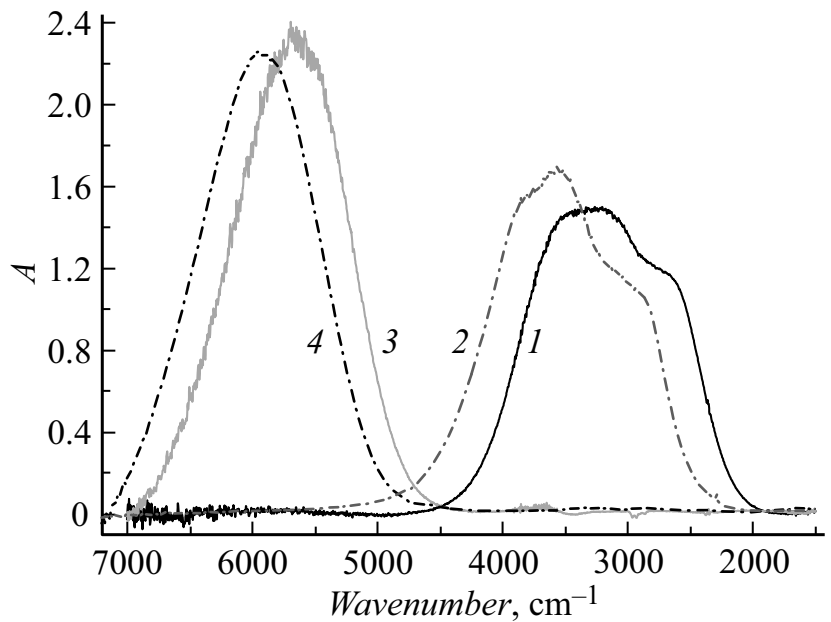

Pис. 2. Спектры поглощения примесей ионов и $\mathrm{Fe}^{2+}$ в $\mathrm{ZnSe}(1), \mathrm{Fe}^{2+}$ в $\mathrm{ZnS}(2), \mathrm{Cr}^{2+}$ в $\mathrm{ZnSe}(3)$ и $\mathrm{Cr}^{2+}$ в $\mathrm{ZnS}(4)$.

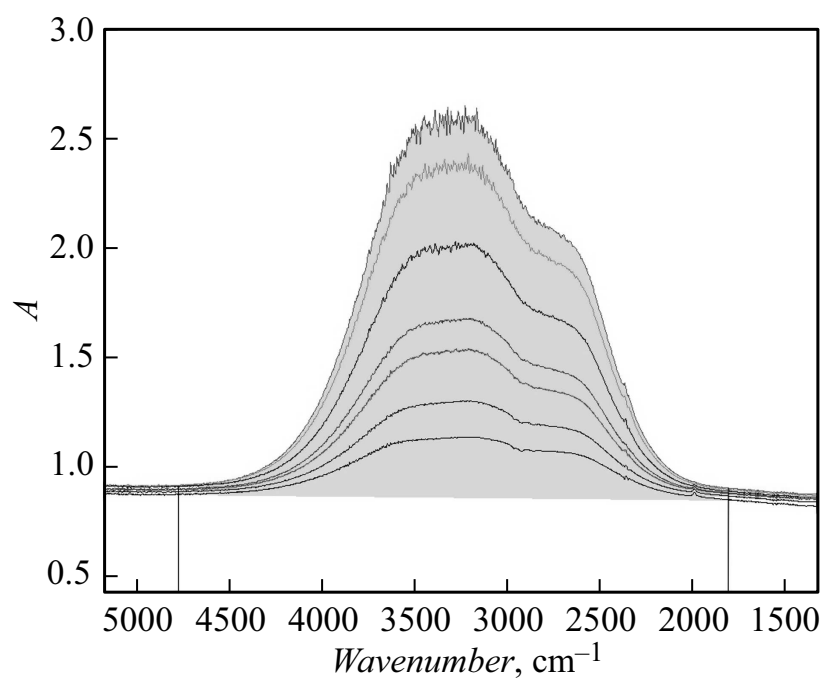

Pис. 3. ИК спектры поглощения железа в образце $\mathrm{ZnSe}$ в нескольких точках области сканирования вдоль направления диффузии допанта. Серым цветом указана площадь интегрирования.

размера образца в направлении диффузии и наблюдаемой толщины диффузионного слоя (рис. 1).

В каждой точке производилась запись ИК спектра пропускания образцов, которые пересчитывались в спектры поглощения (рис. 2) в соответствии с законом БугераЛамберта-Бера, с помощью выражения

$$
A=\ln \left(T_{b} / T_{s}\right)
$$

где $A-$ оптическая плотность, $T_{b}$ - пропускание фона и $T_{s}$ - пропускание исследуемого образца.

Значения волновых чисел максимумов полос поглощения, соответствующих электронным переходам примесей двухвалентных железа и хрома, используемых для определения их концентрации, приведены в таблице.
Положения максимумов полос примесей ионов $\mathrm{Fe}^{2+}$ и $\mathrm{Cr}^{2+}$ в халькогенидах цинка и соответствующие сечения поглощения [4]

\begin{tabular}{c|c|c|c|c}
\hline \multirow{2}{*}{$\begin{array}{c}\text { Халькогенид } \\
\text { цинка }\end{array}$} & \multicolumn{4}{|c}{ Примесь } \\
\cline { 2 - 5 } & \multicolumn{2}{|c}{$\mathrm{Fe}^{2+}$} & \multicolumn{2}{c}{$\mathrm{Cr}^{2+}$} \\
\cline { 2 - 5 } & $v, \mathrm{~cm}^{-1}$ & $\sigma, 10^{-18} \mathrm{~cm}^{2}$ & $v, \mathrm{~cm}^{-1}$ & $\sigma, 10^{-18} \mathrm{~cm}^{2}$ \\
\hline $\mathrm{ZnSe}$ & 3190 & 0.97 & 5630 & 1.0 \\
$\mathrm{ZnS}$ & 3562 & 0.92 & 5900 & 1.1
\end{tabular}

В полученных спектрах с целью повышения чувствительности и точности измерений нами определялись площади соответствующих полос поглощения ионов $\mathrm{Fe}^{2+}$ и $\mathrm{Cr}^{2+}$. Для этого проводилась базовая линия, и выбирались пределы интегрирования общие для конкретной примеси в данном материале, как это показано на рис. 3.

Построение зависимости значений оптической плотности от координаты позволило определить распределительный профиль допанта по образцу, как это показано на рис. 1.

\section{3. Определение концентрационных профилей ионов $\mathrm{Fe}^{2+}$ и $\mathrm{Cr}^{2+}$}

Концентрацию ионов $\mathrm{Cr}^{2+}$ и $\mathrm{Fe}^{2+}$ оценивали по формуле, которая следует из закона Бугера-Ламберта-Бера,

$$
C_{\mathrm{Cr}, \mathrm{Fe}}=\frac{A_{l}}{\sigma l}
$$

где $C_{\mathrm{Cr}, \mathrm{Fe}}-$ концентрация ионов $\mathrm{Cr}, \mathrm{Fe}, A_{I}$ - значение оптической плотности в максимуме поглощения, $\sigma$ сечение поглощения, $l$ - толщина образца $(\mathrm{cm})$.

Значения сечений поглощения ионов $\mathrm{Cr}^{2+}$ и $\mathrm{Fe}^{2+}$ в халькогенидах цинка приведены в таблице.

Для определения концентрации допанта необходимо было вычислить коэффициенты пропорциональности $F$, связывающие площадь под кривой поглощения $A_{S}$ с пиковым значением оптической плотности $A_{I}$ :

$$
F=A_{S} / A_{I}
$$

Для $\mathrm{Fe}^{2+}$ в $\mathrm{ZnS}$ и $\mathrm{ZnSe}$ коэффициенты пропорциональности $F$ оказались равны $1460 \pm 140$ и $1300 \pm 120$ соответственно. Для $\mathrm{Cr}^{2+}$ в $\mathrm{ZnS}$ и $\mathrm{ZnSe}$ коэффициенты пропорциональности $F$ составили значения $1210 \pm 120$ и $1120 \pm 100$ соответственно.

Результаты определения концентрационных профилей железа и хрома в образцах халькогенидов цинка с помощью прецизионной ИК спектроскопической методики представлены на рис. 4, 5 .

Отличительной особенностью данной методики является то, что она позволяет определять концентрационные профили при солегировании несколькими примесями, так как в спектре одного образца линии примесей 
железа и хрома хорошо разрешаются (рис. 2). На рис. 6 приведены диффузионные профили в образце $\mathrm{ZnSe}$, легированным железом с двух сторон и хромом с одной стороны.

\section{2. Метрологические характеристики методики}

\section{1. Проверка правильности}

Для проверки правильности ИК спектроскопической (ИКС) методики нами было проведено сравнение концентрационных профилей, полученных методами ИКС и ЛМС в одних и тех же образцах. Измерения методом ЛМС проводили на лазерном масс-спектрометре с двойной фокусировкой и фотографической регистрацией спектров ЭМАЛ-2. Испарение и ионизация пробы в

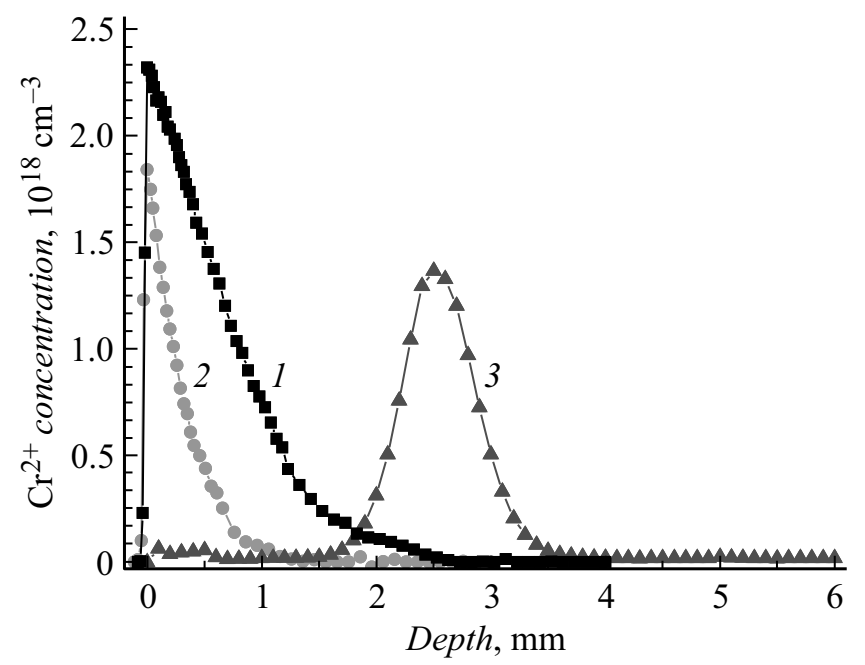

Рис. 4. Распределение ионов $\mathrm{Cr}^{2+}$ в образцах $\mathrm{ZnSe}(1)$ и $\mathrm{ZnS}$ (2) (внешнее легирование, с одной стороны) и в образце $\mathrm{ZnSe}$ (3) (внутреннее легирование).

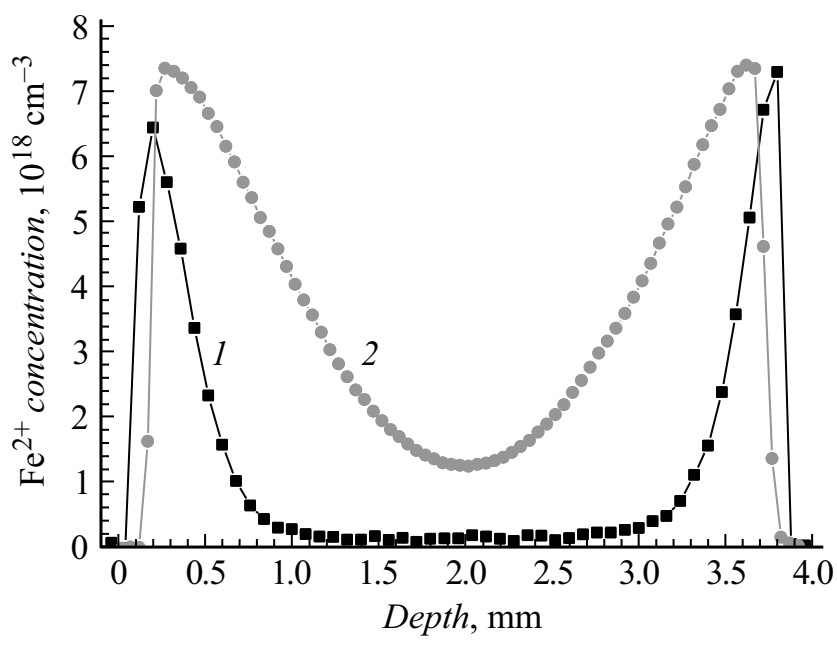

Рис. 5. Распределение ионов $\mathrm{Fe}^{2+}$ в образцах $\mathrm{ZnSe}(1)$ и $\mathrm{ZnS}$ (2) (внешнее легирование, с двух сторон).

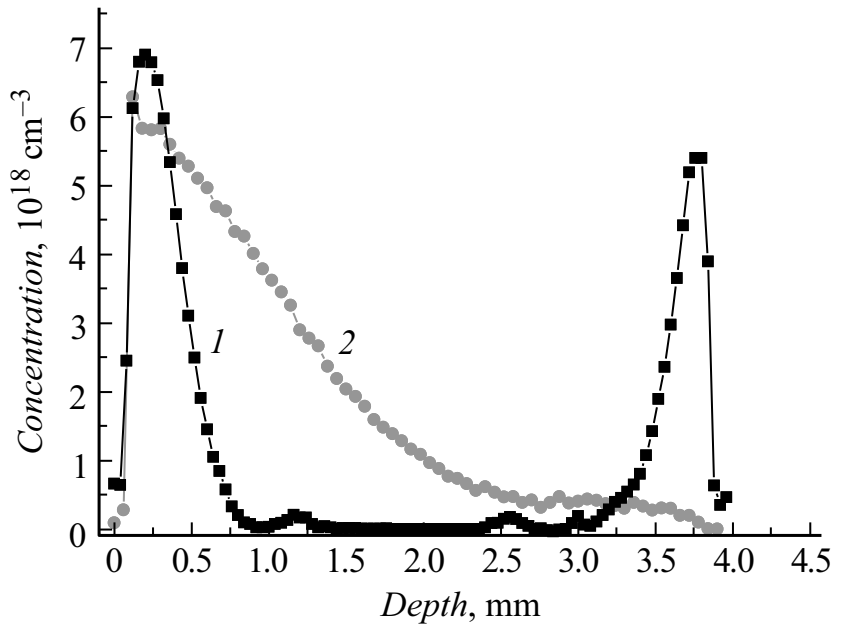

Рис. 6. Распределение ионов $\mathrm{Fe}^{2+}(1)$ и $\mathrm{Cr}^{2+}$ (2) в одном образце $\mathrm{ZnSe}$.

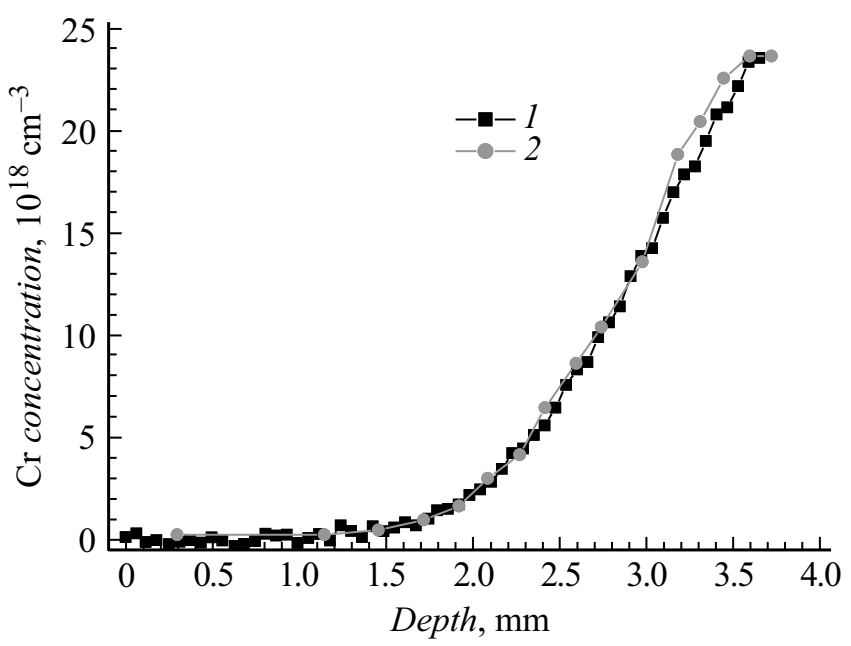

Рис. 7. Сравнительный анализ результатов определения концентрационных профилей хрома в образце $\mathrm{ZnSe}$ методами ИК спектроскопии с ИК микроскопом (1) и лазерной массспектрометрии (2).

ЛМС происходит при сканировании поверхности пробы сфокусированным лазерным излучением с плотностью мощности $\approx 5 \cdot 10^{9} \mathrm{~W} / \mathrm{cm}^{2}$. Жесткие условия облучения обеспечивают практически полную начальную ионизацию материала пробы [13], а регистрируемый спектр представлен в основном только одно- и двухзарядными ионами элементов. Источником излучения служил импульсный одномодовый лазер ИЛТИ203 (длина волны излучения $1.06 \mu \mathrm{m}$, энергия в импульсе $\sim 20 \mathrm{~mJ}$, длительность импульса $20 \mathrm{ns,} \mathrm{диаметр}$ пятна фокусировки $\approx 70 \mu \mathrm{m})$. Скорость сканирования составляла $1 \mathrm{~mm} / \mathrm{s}$ при частоте повторения лазерных импульсов $50 \mathrm{~Hz}$. Толщина испаряемого слоя за один проход составляла $\approx 1-2 \mu \mathrm{m}$. Спектры регистрировали на фотопластины Ilford Q2. Концентрацию легиру- 


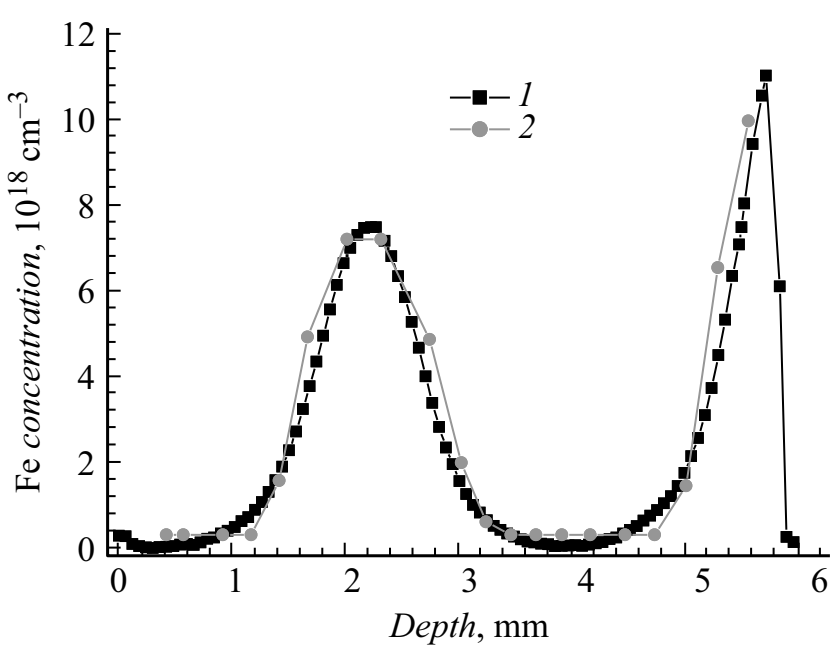

Рис. 8. Сравнительный анализ результатов определения концентрационных профилей железа в образце $\mathrm{ZnSe}$ методами ИК спектроскопии с ИК микроскопом (1) и лазерной массспектрометрии (2).

ющих элементов оценивали по отношению количества однозарядных ионов определяемого элемента к количеству однозарядных ионов матрицы, определенным по интегральным характеристикам линий массспектра.

Результаты сравнительного анализа, представленные на рис. 7,8, показали, что распределения примесей хрома и железа, измеренные различными методами, совпадают в пределах погрешности методик. Относительная погрешность измерений концентрации для ИКС не превышала $15 \%$, а для метода ЛМС составляла $20-30 \%$ в исследованном диапазоне концентраций.

\section{2. Погрешность методики и пределы обнаружения}

Основными составляющими погрешности ИК спектроскопического метода являются инструментальная, связанная с конечной точностью определения оптической плотности и толщины образца, и случайная (угол падения светового пучка на образец, температурный режим прибора и т.д.). Погрешность измерения толщины образца составляла $\pm 0.01 \mu \mathrm{m}$.

Погрешность единичного измерения данным методом с использованием ИК фурье-спектрометра составляла $<1 \%$. Погрешность определения используемого нами коэффициента пропорциональности $F$ для примесей железа и хрома составляла $\pm 10 \%$. Суммарная погрешность методики не превышала 15\% установленной величины.

Пределы обнаружения для примеси двухвалентного железа и хрома в образцах $\mathrm{ZnS}$ и $\mathrm{ZnSe}$, оцененные по 3-s-критерию для доверительной вероятности 0.95 , находились на уровне $(1-3) \cdot 10^{17} \mathrm{at} / \mathrm{cm}^{-3}$.

\section{Заключение}

Представленные результаты показывают широкие возможности определения методом ИК спектроскопии с ИК микроскопом концентрационных профилей допанта в виде ионов $\mathrm{Fe}^{2+}$ и $\mathrm{Cr}^{2+}$ в халькогенидах цинка. Разработанная методика позволяет осуществлять прецизионный, экспрессный и неразрушающий контроль поведения допанта в лазерных средах на основе халькогенидов цинка. Отличительной особенностью методики является возможность определения диффузионных профилей при солегировании халькогенидов цинка несколькими примесями.

Работа выполнена при финансовой поддержке Российского фонда фундаментальных исследований (грант 15-43-02312 р_поволжье_а), в части изготовления и исследования образцов халькогенидов цинка, легированных железом, и по теме Государственного задания № 0095-2016-0015 в части изготовления и исследования образцов халькогенидов цинка, легированных хромом.

\section{Список литературы}

[1] Kuck S. // J. Alloys and Compounds. 2002. Vol. 341. N 1-2. P. 28-33. doi: org/10.1016/S0925-8388(02)00094-4

[2] Fedorov V.V., Mirov S.B., Gallian A., Badikov V.V., Frolov M.P., Korostelin Yu.V., Kozlovsky V.I., Landman A.I., Podmar'kov Yu.P., Akimov V.A., Voronov A.A. // IEEE J. Quant. Electron. 2006. Vol. 42. N 9. P. 907-917. doi: 10.1109/JQE.2006.880119

[3] Mirov S.B., Fedorov V.V., Martyshkin D.V., Moskalev I.S., Mirov M.S., Gapontsev V.P. // Opt. Mater. Express. 2011. Vol. 1. N 5. P. 898-910. doi: 10.1364/OME.1.000898

[4] Mirov S.B., Fedorov V.V., Martyshkin D.V., Moskalev I.S., Mirov M.S., Vasilyev S.V. // IEEE J. Selected Topics In Quant. Electron. 2015. Vol. 21. N 1. P. 1601719. doi: 10.1109/JSTQE.2014.2346512

[5] Vasilyev S., Moskalev I., Mirov M., Smolsky V., Mirov S., Gapontsev V. // Laser Technik J. 2016. Vol. 13. N 4. P. 24-27. doi: 10.1002/latj.201600022

[6] MacDonald John R., Beecher Stephen J., Lancaster Adam, Berry Patrick A., Schepler Kenneth L., Mirov Sergey B., Kar Ajoy K. // Opt. Express. 2014. Vol. 22. N 6. P. 7052 7057. doi: $10.1364 /$ OE.22.007052

[7] Martinez A., Williams L., Fedorov V., Mirov S. // Opt. Mater. Express. 2015. Vol. 5. N 3. P. 558-565. doi: 10.1364/OME.5.000558

[8] Родин С.А., Балабанов С.С., Гаврищук Е.М., Еремейкин О.Н. // Опт. журн. 2013. Т. 80. № 5. С. 8993. [Rodin S.A., Balabanov S.S., Gavrishchuk E.M., Eremeykin O.N. // J. Opt. Technol. 2013. Vol. 80. N 5. P. 325 328.] doi: $10.1364 / J O T .80 .000325$

[9] Ваксман Ю.Ф., Павлов В.В., Ницук Ю.А., Пуртов Ю.Н., Насибов А.С., Шапкин П.В. // ФТП. 2005. Т. 39. Вып. 4. C. 401-404. [Vaksman Yu.F., Pavlov V.V., Nitsuk Yu.A., Purtov Yu.N., Nasibov A.S., Shapkin P.V. // Semiconductors. 2005. Vol. 39. N 4. P. 377-380.] doi: org/10.1134/1.1900247 
[10] Ваксман Ю.Ф., Нииук Ю.А., Яиун В.В., Насибов А.С., Шапкин П.В. // ФТП. 2010. Т. 44. Вып. 4. С. 463-466. [Vaksman Yu.F., Nitsuk Yu.A., Yatsun V.V., Nasibov A.S., Shapkin P.V. // Semiconductors. 2010. Vol. 44. N 4. P. 444 447.] doi: org/10.1134/S1063782610040068

[11] Ndap J.O., Chattopadhyay K., Adetunji O.O., Zelmon D.E., Burger A. // J. Cryst. Growth. 2002. Vol. 240. P. 176-184.

[12] Ильичев Н.Н., Шапкин П.В., Насибов А.С., Мосалева C.E. // Неорган. матер. 2007. Т. 43. № 10. C. 1175-1178. [Ilichev N.N., Mosaleva S.E., Shapkin P.V., Nasibov A.S. // Inorg. Mater. 2007. Vol. 43. N 10. P. 1050 1053.] doi: $10.1134 / \mathrm{S} 0020168507100044$

[13] Trace Analysis by Mass Spectrometry / Ed. by Arthur J. Ahearn. NY.; London: Academic Press, 1972. 474 p. 